\title{
Electron microscope characteristics of inhaled chrysotile asbestos fibre
}

\author{
F. D. POOLEY \\ Department of Mineral Exploitation, University College, Cardiff
}

\begin{abstract}
Pooley, F. D. (1972). Brit. J. industr. Med., 29, 146-153. Electron microscope characteristics of inhaled chrysotile asbestos fibre. Specimens from 300 lungs have been examined under the electron microscope to determine the morphology and diffraction characteristics of any chrysotile asbestos they contained. In 120 cases, material was prepared by alkali digestion and the residual dust was examined. In all cases standard 6-micron histological slides were partially ashed before the residue was transferred to the electron microscope grids. Of the 300 specimens examined, 20 came from men with prolonged industrial exposure to chrysotile, 87 from cases of mesothelioma, and the remainder from control groups drawn from rural and industrial populations.

Chrysotile fibres were readily identified by the characteristic polycrystalline diffraction pattern. The hollow appearance of the single fibres and their shape and arrangement also help in the identification. Specimens from men without industrial exposure contained either single short fibres or aggregates scattered throughout the lungs. In specimens from industrially exposed men, fibres were very numerous and found as strands of single fibres mainly grouped together in discrete locations. Ferruginous bodies were found rarely and only on straight fibre bundles of over several micrometers in length.
\end{abstract}

Chrysotile asbestos which comprises over $90 \%$ of the total asbestos mineral used by our industrial society is a very unique polymorph of the mineral serpentine. It is composed of single, very fine fibres which have been shown by Maser, Rice, and Klug (1960) and Yada (1967) to be less than $30 \mathrm{~nm}(300 \AA)$ in diameter. When seen in hand specimens or under the optical microscope, however, only strands or aggregates of these fine fibres are observed.

Chrysotile has the ability to form a very large variety of particle shapes and sizes because of the very fine nature of its single fibre structure. Because of this large variation in particle morphology, it is possible to define only the size of the single chrysotile fibril. It is almost impossible to define particles of larger size than the single fibril by any single parameter as strands composed of large numbers of single fibrils often branch and bush at their ends and intertwine with other strands to become irregular aggregates (Fig. 1).
The degree of aggregation obtained in any particular chrysotile dust sample is governed by the mechanical treatment the sample has received. Vorwald, Durkan, and Pratt (1951) found that ballmilled chrysotile had a great tendency to form small spherules which prevented the efficient dispersion of the material as fibres in their animal inhalation studies. The ability of chrysotile fibres to form such aggregates thus implies that it is impossible to manufacture a chrysotile dust with any specific dimensions and that the characteristics of chrysotile dust clouds will vary with the method of production of the particles. Speil and Leineweber (1969) show that the degree of length disintegration of fibre bundles depends not only upon the severity of the mechanical action imposed on the sample, but also upon the brittleness or harshness of the mineral. They also found that the fibrous nature, together with the actual structure, of the mineral can be completely 


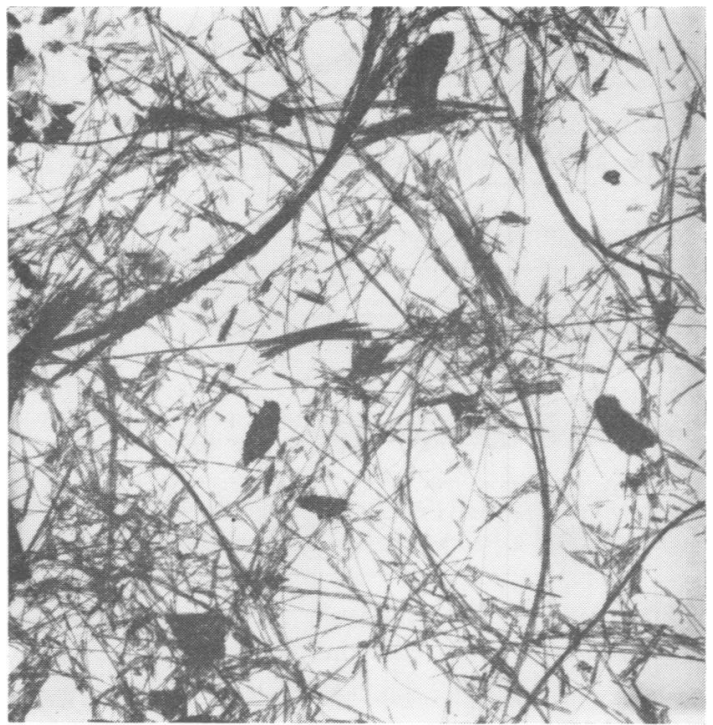

FIG. 1. A sample of chrysotile dust particles $(\times 2000)$.

destroyed when intensive grinding of a chrysotile sample is performed.

Because of the heterogeneous nature of chrysotile dust particles, a number of questions can be raised concerning the influence of the particle form on both the aerodynamic behaviour of the dust when airborne, and also the form in which it may be a danger to health.

Because of lack of a more specific method of identification, light microscopists have been unwilling to identify fibres of less than $3: 1$ aspect ratio as chrysotile. However, Timbrell, Pooley, and Wagner (1970) observed that chrysotile seen in lung tissue with the electron microscope bears little resemblance to the same material viewed by optical means. A similar result by Lynch and Ayer (1968) obtained from the examination of airborne chrysotile dust particles showed that the electron microscope was essential for the study of the majority of chrysotile dust particles which could not be resolved in the optical microscope.

Some doubt has been expressed about the prevalence of asbestos in the lungs of the general population of the industrial countries of the western world who are not occupationally exposed to asbestos. Gross, deTreville, and Haller (1969) found that they could not identify chrysotile in the core of 28 ferruginous bodies extracted from the lungs of urban dwellers not occupationally exposed to asbestos in America. Langer (1970), however, states that the analysis of a number of ferruginous bodies gave results which were consistent with magnesium-leached chrysotile. Chrysotile has been shown to be a very common constituent of the dust contained in the lungs of a rural population group in Great Britain by Pooley, Oldham, Um, and Wagner (1970) and also of a city population group in America by Langer, Selikoff, and Sastre (1971). As chrysotile appears to be rarely detected in the cores of ferruginous bodies found in the lung and yet appears to be a common constituent of environmentally exposed lung tissue, it seems that greater effort should be made to establish the presence and characteristics of this mineral in lung tissue of those people likely to have been exposed to dusts containing it.

Chrysotile is the only asbestos mineral which can at present be positively identified as particles less than 1 micron in size. This is partly because of its unique morphology but also because the mineral gives very characteristic electron diffraction patterns when subjected to diffraction analysis in the electron microscope. Therefore, once it is detected in lung tissue, there is no difficulty whatsoever in establishing its identity with the aid of the electron microscope.

This paper reports the characteristics of chrysotile fibre found in lung tissue of people occupationally exposed to chrysotile asbestos and also in the tissue of random samples of the general population. The results were obtained from a study of material drawn from a wide range of environments, including those who lived in rural, urban, and industrial areas, and also from persons previously employed in the production and processing of chrysotile asbestos. No attempt will be made to report the incidence of chrysotile obtained from the cases examined as this information is to be published separately. Approximately 300 cases have been examined and these break down into the groups listed in the Table.

TABLE

\begin{tabular}{|c|c|c|}
\hline Source & Description & Number of cases \\
\hline $\begin{array}{l}\text { Dorchester, } \\
\text { England }\end{array}$ & $\begin{array}{l}\text { General population } \\
\text { group }\end{array}$ & 48 \\
\hline $\begin{array}{l}\text { Liverpool, } \\
\text { England }\end{array}$ & $\begin{array}{l}\text { General population } \\
\text { group }\end{array}$ & 40 \\
\hline $\begin{array}{l}\text { Malmö, } \\
\text { Sweden }\end{array}$ & $\begin{array}{l}\text { Pleural and peritoneal } \\
\text { mesothelioma }\end{array}$ & 33 \\
\hline $\begin{array}{l}\text { Malmö, } \\
\text { Sweden }\end{array}$ & $\begin{array}{l}\text { General population } \\
\text { controls }\end{array}$ & 32 \\
\hline $\begin{array}{l}\text { London, } \\
\text { England }\end{array}$ & $\begin{array}{l}\text { Retrospective general } \\
\text { population group }\end{array}$ & 45 \\
\hline Canada & Mesothelioma cases & 16 \\
\hline Holland & Mesothelioma cases & 28 \\
\hline Holland & Mesothelioma controls & 13 \\
\hline $\begin{array}{l}\text { Great } \\
\text { Britain }\end{array}$ & Mesothelioma cases & 18 \\
\hline $\begin{array}{l}\text { Great } \\
\text { Britain and } \\
\text { South } \\
\text { Africa }\end{array}$ & $\begin{array}{l}\text { Industrial exposure } \\
\text { group }\end{array}$ & 20 \\
\hline
\end{tabular}




\section{Methods and materials}

The lung material examined was received as standard 6-micron histological sections in paraffin wax, but in a large number of cases larger portions of formalin-fixed tissue were available from which digested tissue extracts were prepared. The digestion technique employed was that formulated by Gold (1967), in which diced tissue is dissolved away in a $40 \%$ solution of potassium hydroxide at a temperature between 60 and $100^{\circ}$.

Both forms of specimens were prepared for electron microscope examination as follows:

(a) The digested lung residues were transferred directly to electron microscope grids covered with a carbon support film by allowing a drop of the residue suspension to dry on the carbon film. Where suspensions also contained large quantities of carbon or organic material, portions were first dried and then ashed at low temperatures, e.g., 400 to $450^{\circ} \mathrm{C}$, and then resuspended in distilled water for examination. During this whole process the tissue residues treated this way were retained in $15-\mathrm{ml}$ glass centrifuge tubes and then resuspended by shaking the tubes by hand. It is known that heating causes chrysotile to become brittle and that any agitation of a heated sample may cause disintegration of particles; care was therefore taken in the interpretation of the results from such preparations. These numbered only 20 in approximately 120 digested residues examined.

(b) Six-micron histological sections were examined from all of the cases listed. They were prepared for an examination of their mineral content by a combination of ashing and transference of the ashed section onto electron microscope grids. The sections on their glass slides were first washed in xylene and alcohol to remove the majority of the embedding paraffin wax. Sections were then ashed at between $450^{\circ} \mathrm{C}$ and $500^{\circ} \mathrm{C}$ on their glass slides in a small muffle furnace. The slides were held in the furnace for a sufficient time to reduce the tissue to a state such that particles of all sizes could be resolved from the tissue remains. Complete ashing destroys all the tissue. Removal of the sections before total ashing was obtained ensured that the outlines of the histological preparation were preserved, while the ashed residue itself still retained some mechanical integrity which was extremely useful in obtaining a successful transference of the partly ashed section onto the electron microscope support grid. An ashing time of 15 minutes at the stated temperatures was found to be sufficient to give the type of specimen required.

The tissue ash plus mineral was removed from the glass slide by an extraction replica process, using a thin film of polyvinyl alcohol as a carrier for the ashed section. The polyvinyl alcohol used was a high viscosity preparation of the polymer and was applied to the ashed section as a $10 \%$ solution by weight in distilled water. A thin film of the polyvinyl alcohol solution was allowed to dry over the ashed section on the glass slide and was then removed, lifting the adhering ash from the slide. This film was then inverted and placed in a standard vacuum coating unit and a layer of carbon was evaporated onto it, thus coating the adhering tissue ash. The preparation was then placed with the plastic film facing downwards on a warm distilled water bath to remove the plastic coating, leaving the tissue ash adhering to the carbon film. Random portions of this film were picked up on electron microscope

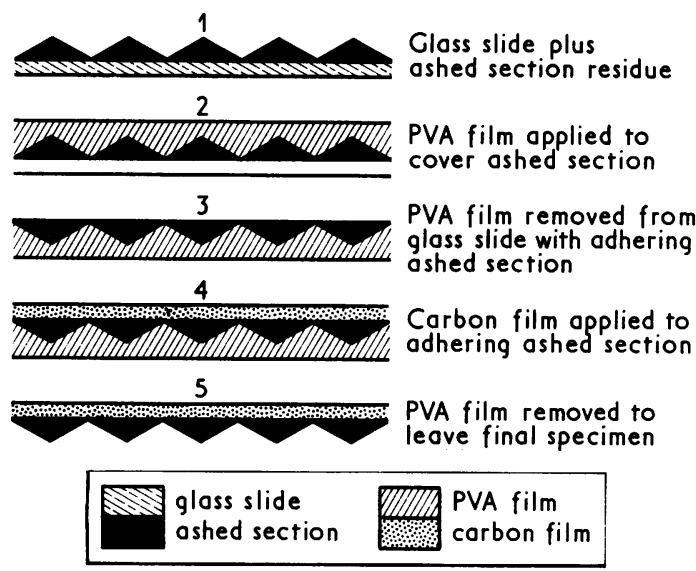

FIG. 2. Schematic presentation of the preparation of ashed thin sections for electron microscope examination.

support grids for examination. A schematic presentation of the preparation procedure is given (Fig. 2).

Both the techniques employed have the advantage that they produce specimens for examination which are representative of the whole mineral content of the lung. There is no bias in the selection of particles as in the case of micromanipulation, for example. The digested lung residues have one distinct advantage, that the mineral is concentrated and so is suitable for specimens where the asbestos fibre content is very low. The ashed thin sections have the advantage that the mineral is located in the final specimen as it was in the tissue, so that, together with the outline of the ashed tissue, a great deal of information about the location and deposition of any fibrous material can be obtained.

\section{Results}

It was found from examination of over 300 lung specimens that chrysotile is an easy fibre type to detect with an electron microscope because of the distinctive fine fibre structure of the mineral. As the particles of chrysotile were usually composed of numerous single fibres, no difficulty was encountered in obtaining good polycrystalline electron diffraction patterns for positive identification of the mineral. Figures 3 and 4 are two examples of the diffraction patterns obtained from chrysotile particles by means of selected area electron diffraction.

Selected area electron diffraction patterns obtained from chrysotile dust particles vary in character, depending partly on the size of the dust particle from which the diffraction pattern is obtained, and also on the size of the diffraction aperture employed when recording the pattern. The larger the diffraction aperture used, the larger the area of the particle or specimen which is selected and thus contributes to the pattern. As the size of chrysotile particles increases 


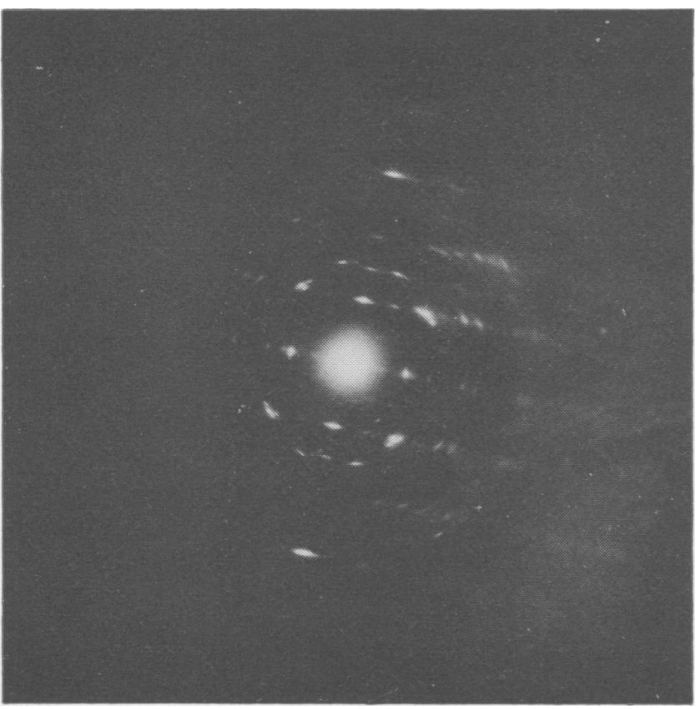

FIG. 3.

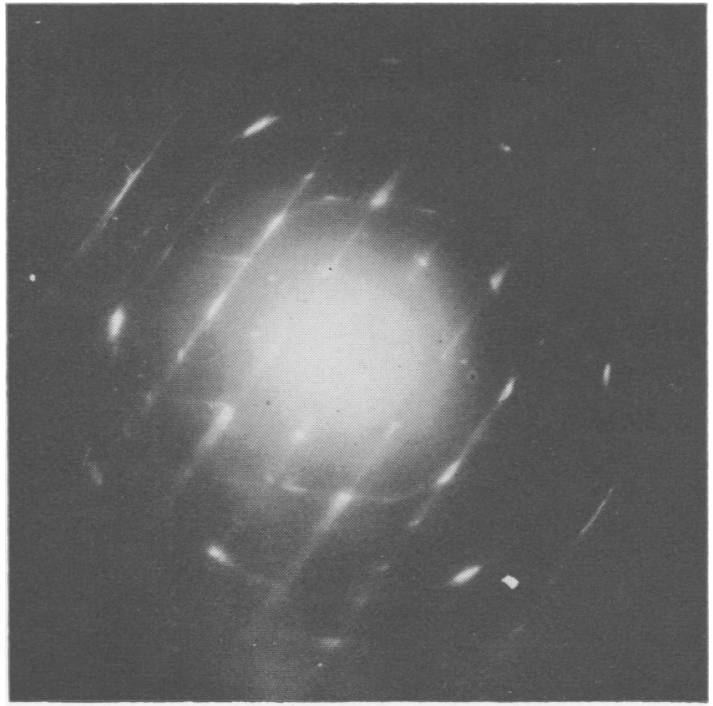

FIG. 4.

FIGS 3 and 4. Characteristic selected area electron diffraction patterns obtained from chrysotile dust particles.

the number of single fibrils from which they are composed also increases. Diffraction patterns obtained from particles of chrysotile larger than a single fibril are produced from a number of fibrils and are therefore polycrystalline in character. In some circumstances, where the diffraction aperture defines a large number of randomly orientated crystallites, Debye-Scherrer ring patterns are obtained. As the majority of selected area diffraction patterns from chrysotile particles are polycrystalline, the characteristic features of the patterns are the curved reflections which can be observed in Figures 3 and 4. If the curved reflections are sufficiently pronounced and the pattern is not too distorted, the distances between diametrically opposed reflections can be measured and the interplanar spacings or 'd' values producing the reflections can be calculated and compared with data obtained from reference samples. Comparison of the unknown diffraction pattern with the diffraction patterns obtained from known particles of chrysotile is also useful in order to compare the position of reflections which appear as either arcs or single spots.

The chrysotile particles in lung specimens were all extremely variable as predicted from the examination of dust particles of commercial chrysotile. They varied from bundles or strands of chrysotile fibres of various lengths, sometimes curved and twisted, sometimes straight, to single fibres of chrysotile, again of various lengths and in a variety of attitudes. Aggregated fibres were also found sometimes containing only several small fibres, but also several thousand fine fibres. Examples of these various types of particles are illustrated (Figs 5 to 8).

The great majority of chrysotile fibres detected in lung tissue had developed no ferruginous coating.

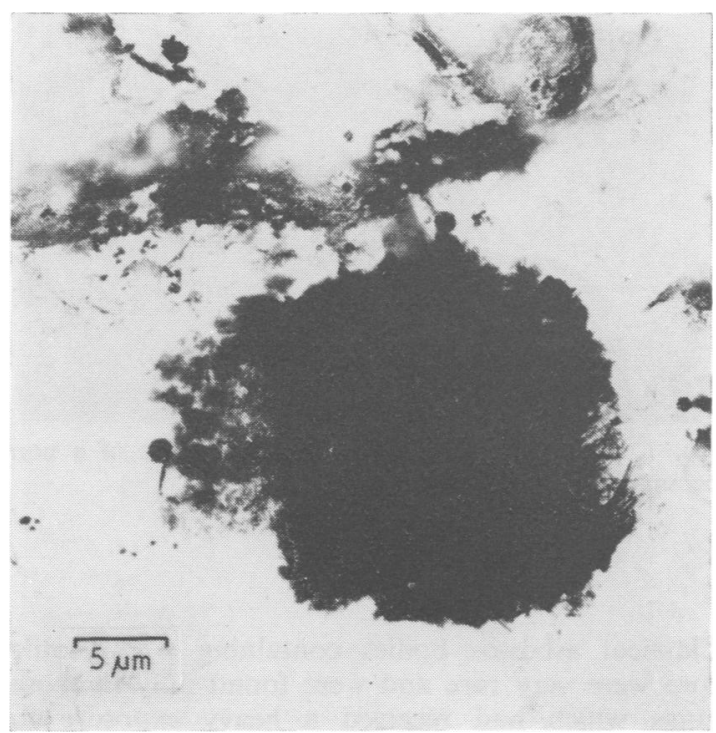

FIG. 5. Large aggregate of chrysotile fibres from a non occupationally exposed case. 


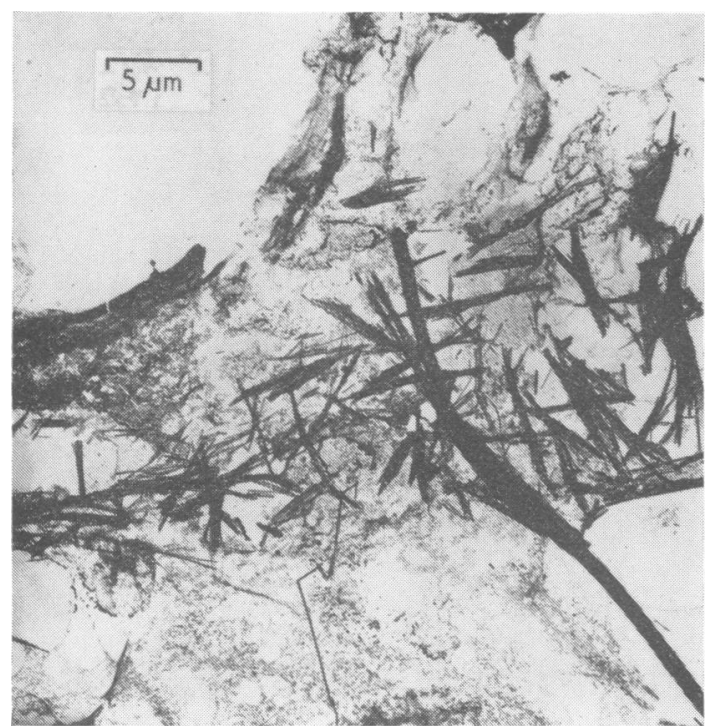

FIG. 6. Bundles of chrysutile fibre detected in an occupationally exposed case.

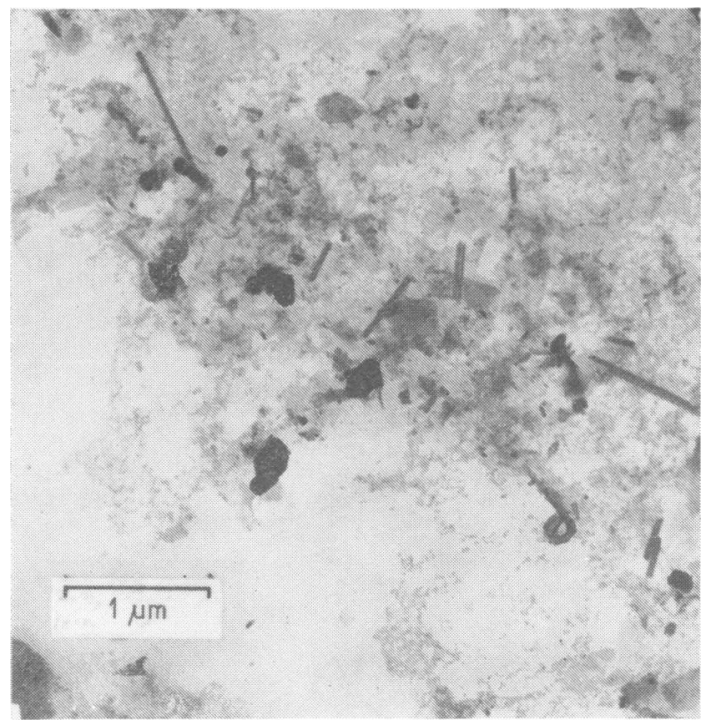

FIG. 7. Single chrysotile fibres characteristic of a non occupationally exposed case.

Classical asbestos bodies containing a chrysotile core were very rare and were found only in those lungs which had received a heavy exposure to chrysotile fibre. Free or uncoated chrysotile fibres in the heavily exposed specimens outnumbered coated fibres by some several thousand to one. An example of one classical asbestos body formed on a bundle of chrysotile fibres is shown (Fig. 9).

The examination of chrysotile particles in those specimens prepared from ashed thin sections sug-

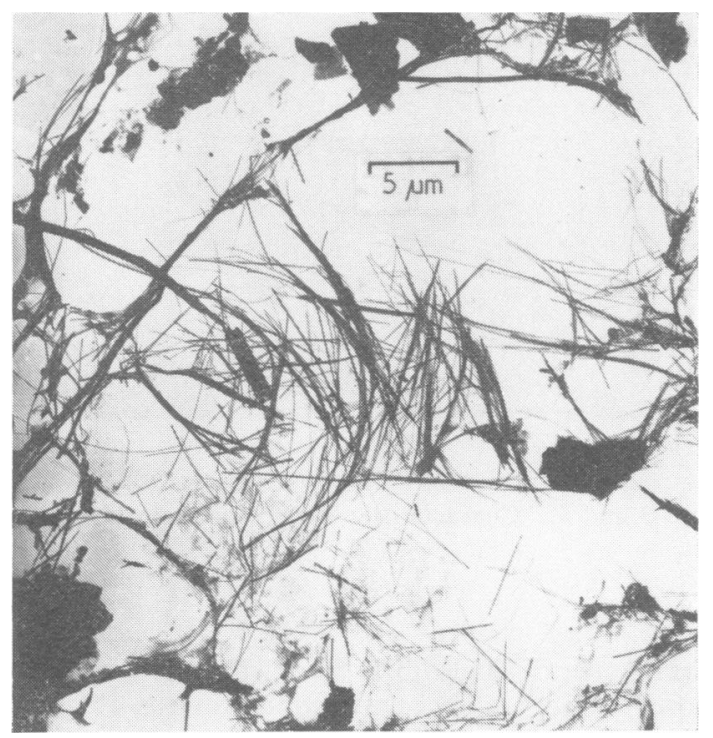

FIG. 8. Large, loose aggregates and long, single chrysotile fibres of the type observed in occupationally exposed cases.

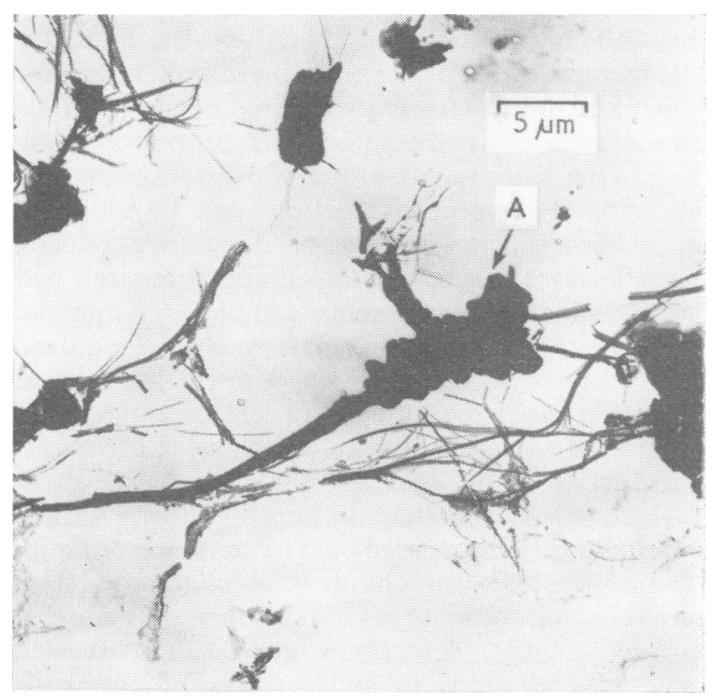

FIG. 9. Asbestos body formation (A) on a bundle of chrysotile fibre, from an occupationally exposed case. 
gested that some of the particles may have changed in appearance after deposition in the lung. Some of the less compact fibre aggregates could have been produced by opening of the fibre bundles under the action of lung fluids or they could also have been formed by the deposition of a large number of particles in one particular location. Fibres and bundles of fibres were often found conforming to the shape of airways, while the majority of the chrysotile particles were grouped together in large clusters. These large clusters were often detected at the bifurcation of small airways and illustrated the tendency that fibrous particles have to be preferentially deposited at positions where their extreme shapes interfere with the ability to change their direction of motion, as proposed by Timbrell (1965). Besides these large clusters of particles, finer chrysotile fibres were also found scattered throughout the lung sections. Some examples of the various deposits from ashed, thin sections of lung tissue are illustrated (Figs 10 to 12).

As expected from the examination of prepared chrysotile dusts, the particles of chrysotile seen in preparations of lung tissue of necropsy cases varied a great deal in character. Although it has not been found possible to apply any rigid dimensions to the particles of chrysotile detected, it has been found possible to divide the lung specimens examined into two groups, in each of which chrysotile particles were found mainly in a particular form.

The findings in lungs of men with occupational exposure differed from the control groups in two

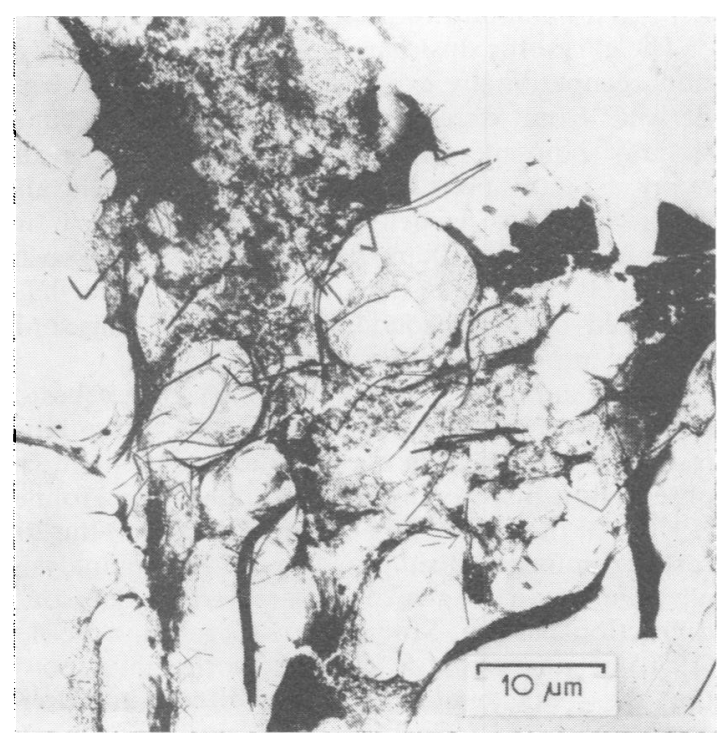

FIG. 10. An area of an ashed section from an occupationally exposed case showing the tissue ash and associated chrysotile fibre.

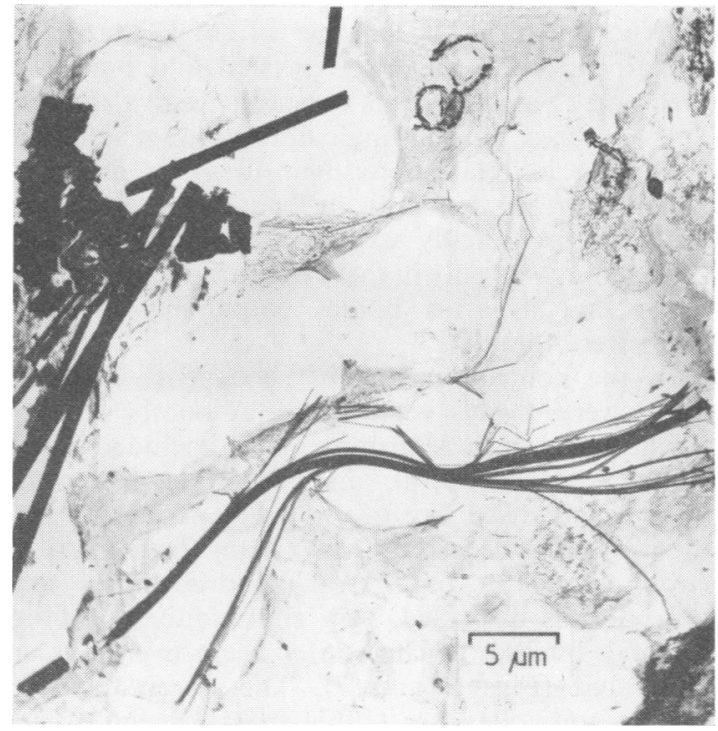

FIG. 11. Ashed section of an occupationally exposed case showing both amphibole and chrysotile fibres.

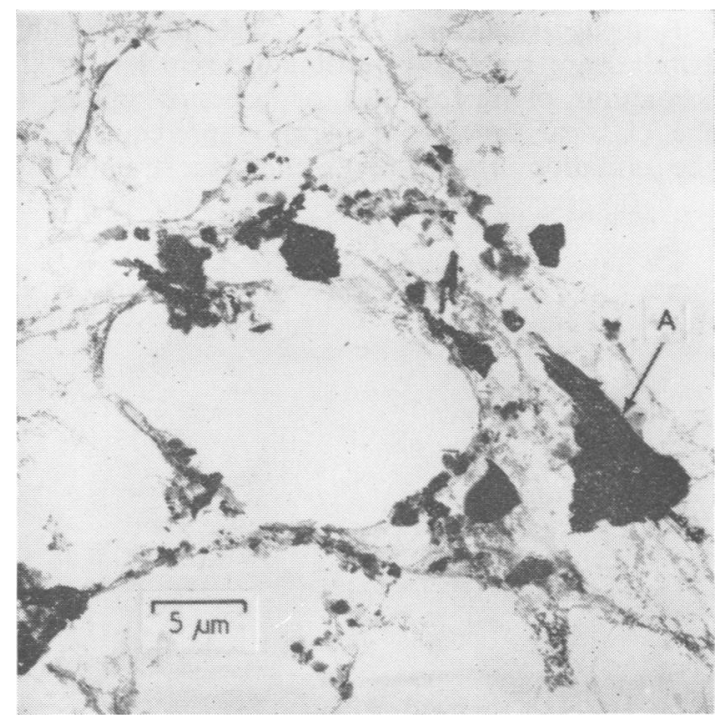

FIG. 12. Fibre aggregate (A) detected in an ashed section from a non occupationally exposed case.

ways. First, there was a great deal more asbestos in the occupational group and, secondly, the kind of fibres and aggregates of fibres was different. In the occupational group the fibre was practically always found in the form of strands, i.e., bundles of single chrysotile fibres. These strands of fibre varied in 
thickness, i.e., in the number of single fibres they contained, and were often twisted and bushed at their ends. Single fibres of chrysotile were also found in these cases, but the single fibres were generally all very long in relation to their diameter and were rarely less than 1 micron in length. An example of these occupationally exposed cases is illustrated (Fig. 13). It was only in these occupationally exposed lungs that asbestos bodies containing chrysotile cores were found.

In the control groups of specimens, chrysotile fibres were always very sparse. A number of preparations from these groups, which included people from industrial, rural, and urban environments, were found to be free of chrysotile. When present, the chrysotile occurred in two main forms: first, as large aggregates of several hundred fibres and, secondly, as dispersed, very short individual fibres or small bundles of chrysotile. These two types are illustrated (Figs 5 and 7). The observations of Langer and colleagues (1971) from a group of non occupationally exposed cases confirm the general picture presented above. Their results show the predominance of single chrysotile fibres over bundles, the majority of the particles detected having a length: diameter ratio of less than 10:1.

Both aggregates and short, single fibres or fibre bundles are apparently unsuitable vehicles for the formation of ferruginous or asbestos bodies of the classical type. In general, a prerequisite for the formation of an asbestos body is a straight fibre

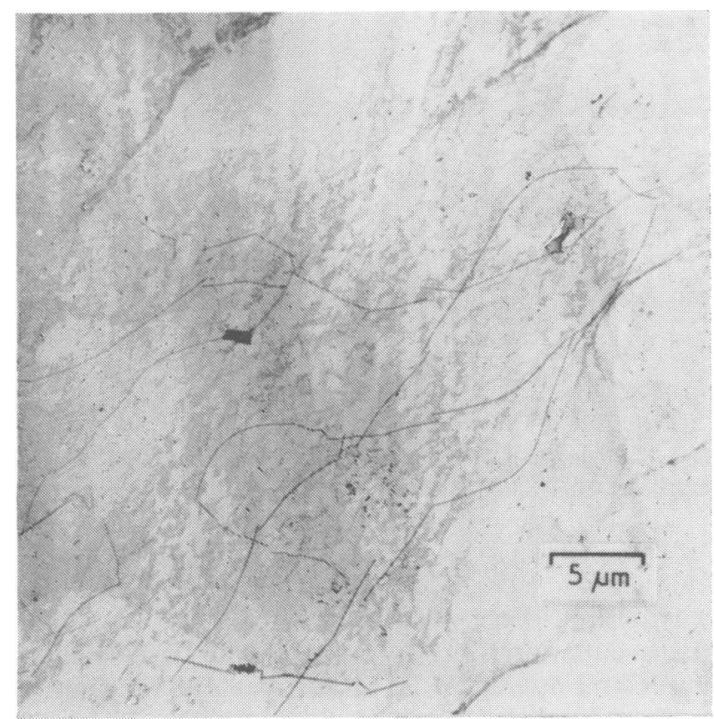

FIG. 13. Long, single chrysotile fibres found distributed throughout the tissue ash of an occupationally exposed case. exceeding several microns in length; rarely did the chrysotile fibres in the non occupationally exposed group have this particular characteristic and in fact no asbestos bodies containing chrysotile cores were found in this group, although bodies on amphibole fibres were detected.

\section{Discussion}

Vorwald et al. (1951) observed that, by reducing the length of the chrysotile dust injected into guinea-pig lungs from 20 to less than 3 microns, they reduced the formation of asbestos bodies to practically nil and those which were observed were found to have formed on the few long fibres which were contained in the -3 micron dust. Similar observations with amphibole fibres confirm the dependence of the formation of the classical asbestos bcdy on fibre length.

The differences in character between chrysotile dust particles contained in the lungs of occupationally and non occupationally exposed persons are not too difficult to comprehend when the production of dust particles is considered. Occupationally exposed individuals generally handle raw fibre which has been treated in such a way that the long fibrous nature of the material is retained as much as possible. Chrysotile asbestos fibre is only commercial because it can be produced in long fibre or strand form. It is therefore safe to say that the majority of dust particles produced by the handling of raw commercial fibre will be fibrous (i.e., strand-like) as the amount of mechanical handling it receives is kept to a minimum to preserve this property.

The chrysotile dust particles found in the lungs of non occupationally exposed persons will have been derived from different sources than in occupationally exposed persons. The sources will be the many asbestos products containing chrysotile and from which dust particles are produced by far more mechanical action than the raw fibre ever receives. It is likely, therefore, that the character of particles produced by the secondary handling of chrysotile asbestos products will be different.

Langer et al. (1971) found that chrysotile asbestos is biologically affected by its residence in the lung, resulting in a loss of its magnesium content, an observation also reported by Morgan and Holmes (1970). Of the chrysotile particles detected in the 300 cases examined and subjected to diffraction analysis, all were found to give the characteristic chrysotile diffraction pattern. Studies by Morgan and Pooley (1970) of magnesium-leached chrysotile have shown that the characteristic chrysotile diffraction pattern can be obtained from fibres with up to $50 \%$ of the magnesium removed. The fibres found and tested in the cases reported in this paper could therefore have lost up to about $50 \%$ of their magnesium content, 
but leaching, it appears, had not proceeded beyond this point.

The detection of chrysotile dust particles in the lungs of persons handling the mineral is to be expected in every case under the optical microscope. The detection of chrysotile dust particles in the lungs of non occupationally exposed persons would not, it would seem, be very likely. This is simply because the fibres are smaller in diameter, and near the power of resolution of the optical microscope, and also because there is little body formation on such fibre.

It is likely that the chrysotile dust inhaled by asbestos workers was freshly made and contained particles of a relatively high sedimentation rate, whereas the control cases would be less likely to be exposed to fresh dust and therefore slow sedimentation or resuspendable particles would predominate in their lungs. This is confirmed by the observations performed on the control cases where aggregates and short individual fibres form the predominant chrysotile particle types detected. Both of these particulate forms possess very much lower sedimentation rates when compared with the fibre bundles found in the occupationally exposed cases.

\section{Conclusions}

Chrysotile fibres in lung sections and residues present a wide variety of patterns due to their small diameter, great variation in length, curved shape, and the tendency to aggregate into bundles of fibrils. No simple description can adequately describe the variety of appearance, but the high specificity of the diffraction pattern enables positive identification of individual fibres which can be selected for examination with the aid of the electron microscope.

The hollow appearance characteristic of single chrysotile fibrils is also useful in substantiating an identification but cannot in itself be considered to be a feature on which positive identification can be made. As in all mineralogical studies, identification must be based on the observation of a number of physical and chemical properties of the material.

The character of chrysotile dust particles found in the lung differs between occupationally and non occupationally exposed individuals. In the former group, the particles are generally found as strands of single fibres, mainly grouped together in discrete locations in the lung. In the latter group, the majority of the chrysotile particles are found as aggregates together with short single fibres and fibre bundles distributed about the lung.

Ferruginous bodies or asbestos bodies have been found to form very rarely on chrysotile particles and only on particles suitable for their formation, i.e., straight fibre bundles over several microns in length. Chrysotile dust particles are therefore not always suitable to act as a nucleus for a classical asbestos body shape. The majority of asbestos bodies seen under the optical microscope may be said to be formed on amphibole asbestos fibres.

This work has been supported by the Medical Research Council and the International Agency for Cancer Research. I should like to thank Dr. J. C. Gilson and Dr. J. C. Wagner for their help in the preparation of this manuscript.

\section{References}

Gold, C. (1967). A simple method for detecting asbestos in tissue. J. clin. Path., $20,674$.

Gross, P., deTreville, R. T. P., and Haller, M. N. (1969). Pulmonary ferruginous bodies in city dwellers. Arch. environm. Hlth, 19, 186-188.

Langer, A. M. (1970). In Applied Seminar on the Laboratory Diagnosis of Disease Caused by Toxic Agents, edited by W. F. Sunderman and F. W. Sunderman, Jr., pp. 126-136. Warren H. Green, St. Louis.

_ Selikoff, I. J., and Sastre, A. (1971). Chrysotile asbestos in the lungs of persons in New York City. Arch. environm. Hlth, 22, 348-361.

Lynch, J. R., and Ayer, H. E., (1968) Measurement of asbestos exposure. J. occup. Med., 10, 21-24.

Maser, M., Rice, V. R., and Klug, H. P. (1960). Chrysotile morphology. Amer. Mineralogist, 45, 680-688.

Morgan, A., and Holmes, A. (1970). Neutron activation techniques in investigations of the composition and biological effects of asbestos. In Pneumoconiosis: Proc. Int. Conference, Johannesburg, 1969, edited by H. A. Shapiro, pp. 52-56. Oxford University Press, Cape Town. , and Pooley, F. D. (1970). Private communication with Health Physics Section Atomic Energy Research Establishment, Harwell.

Pooley, F., Oldham, P., Um, Chang-Hyun, and Wagner, J. C. (1970). The detection of asbestos in tissues. In Pneumoconiosis, Proc. Int. Conference, Johannesburg, 1969, edited by H. A. Shapiro, pp. 108-116. Oxford University Press, Cape Town.

Speil, S., and Leineweber, J. P. (1969). Asbestos minerals in modern technology. Environ. Res., 2, 166-208.

Timbrell, V. (1965) The inhalation of fibrous dusts. Ann. N.Y. Acad. Sci., 132, 255-273.

- Pooley, F., and Wagner, J. C. (1970). Characteristics of respirable asbestos fibres. In Pneumoconiosis, Proc. Int. Conference, Johannesburg, 1969, edited by H. A. Shapiro, pp. 120-125. Oxford University Press, Cape Town.

Vorwald, A. J., Durkan, T. M., and Pratt, P. C. (1951). Experimental studies of asbestosis. Arch. industr. Hyg., $3,1-43$.

Yada, K. (1967). Study of chrysotile asbestos by a high resolution electron microscope. Acta crystallogr., 23. 704-707.

Received for publication July 15, 1971. 